Two-Step Nanoscale Approach for Well-Defined Complex Alkanethiol Films on Au Surfaces

Peer-reviewed author version

NEUPANE, Shova; LOSADA-PEREZ, Patricia; VIVEGNIS, Sebastien; Mekhalif, Zineb; Delhalle, Joseph; Bashir, Asif \& RENNER, Frank (2018) Two-Step Nanoscale Approach for Well-Defined Complex Alkanethiol Films on Au Surfaces. In:

LANGMUIR, 34(1), p. 66-72.

DOI: 10.1021/acs.langmuir.7b02760

Handle: http://hdl.handle.net/1942/26547 
This document is confidential and is proprietary to the American Chemical Society and its authors. Do not copy or disclose without written permission. If you have received this item in error, notify the sender and delete all copies.

\section{Two-step nanoscale approach for well-defined complex alkanethiol films on Au surfaces}

\begin{tabular}{|r|l|}
\hline Journal: & Langmuir \\
\hline Manuscript ID & la-2017-027602.R2 \\
\hline Manuscript Type: & Article \\
\hline Date Submitted by the Author: & n/a \\
\hline Complete List of Authors: & $\begin{array}{l}\text { Neupane, Shova; Universiteit Hasselt Faculteit Wetenschappen, Physics } \\
\text { Losada-Pérez, Patricia; University of Hasselt, Institute of Materials } \\
\text { Research } \\
\text { Vivegnis, Sebastien; Universite de Namur, Chemistry, Laboratory of } \\
\text { Chemistry and Electrochemistry of Surfaces } \\
\text { Mekhalif, Zineb; University of Namur, Chemistry, Laboratory of Chemistry } \\
\text { and Electrochemistry of Surfaces } \\
\text { Delhalle, Joseph; Universite de Namur, Chemistry, Laboratory of Chemistry } \\
\text { and Electrochemistry of Surfaces } \\
\text { Bashir, Asif; Thyssenkrupp Bilstein GmbH, Hans Bilstein Werk Niederkell } \\
\text { Renner, Frank Uwe; Universiteit Hasselt, IMO }\end{array}$ \\
\hline \hline
\end{tabular}




\title{
Two-step nanoscale approach for well-defined complex alkanethiol films on Au surfaces
}

S. Neupane ${ }^{\dagger, *}$ P. Losada-Pérez ${ }^{\dagger, \star, \$}$, S. Vivegnis ${ }^{\dagger, \S}, Z^{2}$. Mekhalif ${ }^{\S}$, J. Delhalle $^{\S}$, A. Bashir, F.U. Renner*, ${ }^{*}$,

${ }^{\dagger}$ Institute for Materials Research (IMO), Hasselt University, 3590 Diepenbeek, Belgium

*IMEC vzw. Division IMOMEC, 3590 Diepenbeek, Belgium

$\S$ Laboratory of Chemistry and Electrochemistry of Surfaces (CES), University of Namur, 61, rue de Bruxelles, B-5000 Namur, Belgium

"Thyssenkrupp Bilstein GmbH, Niederkell 25, 54429 Mandern, Germany

* Corresponding author: Tel.: +32 11 26-8835; frank.renner@uhasselt.be (F.U. Renner)

$\$$ Present address: Soft Matter Physics Laboratory, Université Libre de Bruxelles (ULB), Campus de La Plaine, CP223, Boulevard du Triomphe, 1050 Bruxelles

\begin{abstract}
Controlling the molecular organization of organic self-assembled monolayers (SAM) is of utmost importance in nanotechnology, molecular electronics, and surface science. Here we propose two well-differentiated approaches, double printing based on microcontact printing ( $\mu$-cp) and molecular back-filling adsorption, to produce complex alkanethiol films. The resulting films on model Au surfaces were characterized by atomic force microscopy (AFM), X-ray photoelectron spectroscopy (XPS) and contact angle measurements. Double printing alkanethiols results in clear coexisting regions where no molecular displacement is observed, highlighting the slow diffusion rates of long alkanethiols and large attractive interaction between long alkyl chains. Exposing a single-print $\mu$-cp Au substrate to an additional alkanethiol solution yields the formation of differently-ordered domain boundaries with different thickness and micrometer lateral size. The high order is a result of enhanced molecular mobility and re-structuring during solution backfilling. The formed molecular assemblies constitute an excellent testing ground for nanoscale phenomena that strongly depend on the nanoscale geometrical and chemical features of the surface such as designed functionality or corrosion initiation and inhibition.
\end{abstract}




\section{INTRODUCTION}

Self-assembled thiol monolayers (SAMs) are molecular assemblies of organic constituents formed spontaneously by the adsorption process of molecules in liquid or vapor phase on metal or metal oxide surfaces. ${ }^{1-4}$ The adsorbent molecules or ligands that form SAM structures are composed of a sulfhydryl head group attached to a backbone chain such as, for example alkyl chains in alkanethiols, and eventually terminated by a variety of functionalities. Over the last decades, SAMs have become popular due to their utility for diverse applications such as biosensing platforms, ${ }^{5}$ nano/microfabrication, ${ }^{6}$ and in some cases corrosion prevention. Apart from structural materials and bulk surfaces, thiol modification is also used for functional nanomaterials such as for nanoparticles in electrocatalysis. ${ }^{7}$ For corrosion, thiols find potential use in oil and gas industries, where thiolbased films have been employed as (model) inhibitors for oxidation and corrosion protection and showed inhibition effects on different metallic compounds. ${ }^{8-13}$

Despite many studies on macroscopic corrosion and inhibition effects in the presence of organic molecules and thiols, the initial stages of corrosion and corrosion inhibition at the sub-nanometer or molecular scale are poorly understood. Indeed, understanding of corrosion protection at the molecular level is limited due to the complexity of the involved systems and the special challenges for surface preparation and in-situ characterization. Dealloying of (binary) noble metal alloys is for example one of the simplest scenarios of corrosion, yet the involved mechanisms are still under debate. The presence of thiol inhibitor molecules on Aubased alloys (where an ultrathin nearly-pure Au top-layer forms at the interface) induces localized dealloying with distinct nanoporous Au defect areas. ${ }^{11-13}$ Nanoporous Au has a tendency to shrink in volume,${ }^{14}$ eventually leading to a surface covered with micrometer sized cracks. ${ }^{15}$ The scenario of localized dealloying on Au-based alloys equally depends on the surface crystallographic orientation and on the molecular organization and stability of the 
organic inhibitor monolayer, so far in an uncontrolled manner. The possibility of controlling the spatial distribution and molecular organization of organic monolayers thus provides a promising approach for addressing localized corrosion as well as functionality which may depend on local structure and molecular order. Using microcontact printing ( $\mu$-cp) laterally structured thiol SAMs ${ }^{16-18}$ we earlier revealed that even very low-density thiol areas surrounding the patterns are completely protected and initiation of dealloying proceeds only along the areas with the lowest inhibitor concentration. ${ }^{13,19}$ In line with increasing the defined complexity of organic films and related defects, well-controlled hybrid SAM films including different geometries and length-scales will enable new insights in the mechanisms of molecular functionality. Here we report on the nanoscale formation of complex thiol films beyond a simple homogeneous monolayer which are formed on model surface substrates of ultraflat polycrystalline gold, UFG (Fig.1).

The control of molecular order and disorder of self-assembled monolayers and interfaces is important in many fields of nanophysics, molecular electronics ${ }^{20,21}$ and surface science, yet rarely studied in detail. Beyond our own ultimate goal to understand and control the origin of localized breakdown of organic-molecule-inhibited (dealloying) corrosion, detailed insights in the molecular interactions and structure formation are therefore widely necessary. The understanding and control of lateral (dis)order, such as film domain boundaries, and in particular the understanding of intentional, well-controlled defects is addressed by preparation using a mix of single and double micro-contact printing ( $\mu$-cp) and simple solution back-filling steps ${ }^{22}$ (Fig.1a). Molecular defects are always present even in highly ordered films, but can be reproducibly formed and controlled with the here presented approach. We focus on the organization of hybrid layers consisting of hexa- and octadecanethiol $\left(\mathrm{C}_{16}-\mathrm{SH}\right.$ and $\left.\mathrm{C}_{18}-\mathrm{SH}\right)$ long chain-length alkanethiol SAMs chosen as a representative showcase example. 


\section{MATERIALS AND METHODS}

\section{Chemicals used}

1-Hexadecanethiol $(\geq 95 \%)$ and 1-octadecanethiol $(\geq 98 \%)$ were purchased from Sigma Aldrich. Absolute ethanol ( $\geq 99.85 \%$ ) and 2-propanol ( $\geq 99.7 \%$ ) were obtained from VWR Prolab Chemicals. All chemicals were used without further purification. Alkanethiol solutions were prepared at $1.0 \mathrm{mM}$ concentration in absolute ethanol and sonicated in a bath sonicator (Branson 1510 ultrasonic cleaner) for 5 to $10 \mathrm{~min}$. Then, the alkanethiol solution was filtered through a disposable syringe filter (pore size $0.45 \mu \mathrm{m}$, filter $\varnothing: 15 \mathrm{~mm}$ ) from Macherey-Nagel Gmbh \& Co. (Germany).

\section{Gold substrates}

Ultraflat polycrystalline gold substrates were purchased from Platypus (item no Au. 1000SWTSG, Lot no 15/1001). These substrates are glass chips coated with a $100 \mathrm{~nm}$ gold layer which is template-stripped from a gold-coated silicon wafer template. The fresh template-stripped substrates were used without further cleaning. The local roughness of the UFG surfaces measured by AFM is locally in a range between 0.1 to $0.9 \mathrm{~nm}$ with an RMS value of 0.15 to $0.8 \mathrm{~nm}$ and shows some film growth voids (Fig. 1b, c).

\section{Microcontact printing and backfilling}

Polydimethylsiloxane (PDMS) stamps were fabricated by traditional photolithography techniques $^{23}$. They consist of an array of micrometer-sized squares with micrometer-sized separations among them. Prior to exposure to the alkanethiol solution, the stamps were rinsed with pure ethanol and dried under $\mathrm{N}_{2}$ gas. Afterwards, the stamps were exposed to a $1.0 \mathrm{mM}$ alkanethiol solution for $\sim 30$ seconds and dried gently under $\mathrm{N}_{2}$ gas. The thiol-containing 


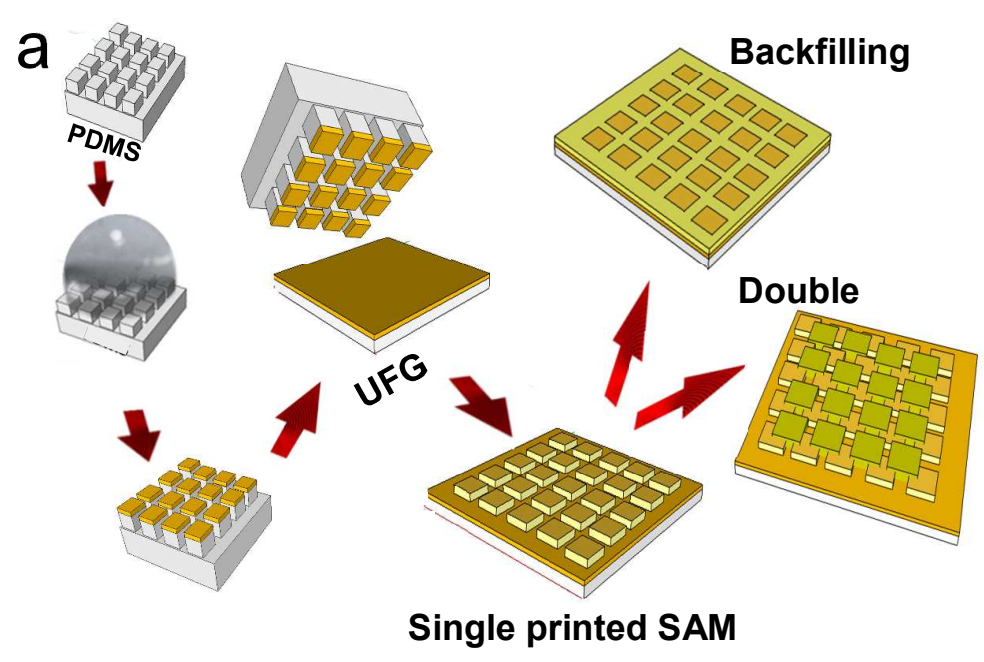

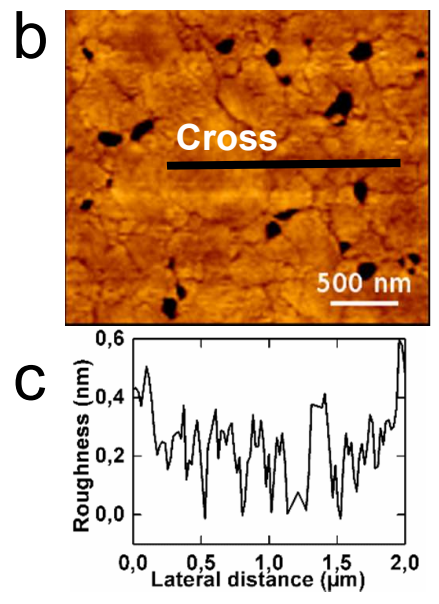

Cross section

Figure 1. (a) Schematic of the multi-step approach: initial microcontact printing step followed by either double printing or solution backfilling. (b) AFM image of a freshly stripped Au surface with (c) Cross section profile.

\author{
Atomic force microscopy \\ AFM experiments were performed using a JPK NanoWizard 3 AFM (JPK Instruments AG, \\ Berlin, Germany) using AC mode in air. Silicon ACTA-50 tips from AppNano with \\ cantilever length $\sim 125 \mu \mathrm{m}$, spring constant $\sim 40 \mathrm{~N} / \mathrm{m}$ and resonance frequency $\sim 300 \mathrm{kHz}$ \\ were used.
}




\section{X-ray photoelectron spectroscopy}

XPS spectra were recorded on a Thermo Scientific K-Alpha spectrometer using a monochromatic Al Ka X-ray source $(1486.6 \mathrm{eV})$. The photoelectrons are collected at $0^{\circ}$ with respect to the surface normal and detected with a hemispherical analyzer. The spot size of the X-ray source on the sample is $200 \mu \mathrm{m}$, and the analyzer is operated with a pass energy of 200 $\mathrm{eV}$ for survey spectra and $50 \mathrm{eV}$ for high resolution core levels spectra with pressure during data acquisition is $\sim 1.10^{-7}$ mbar. Energy step during survey is $1.0 \mathrm{eV}$ and high-resolution spectra $0.08 \mathrm{eV}$. Survey and high-resolution core levels spectra of Au4f, C1s, S2p, O1s and Si2s were performed. The binding energies were corrected by use of the $\mathrm{C} 1 \mathrm{~s}(\mathrm{C}-\mathrm{C} / \mathrm{C}-\mathrm{H})$ peak $(285.0 \mathrm{eV})$ as an energy standard. Peak analysis was carried out by Thermo Avantage software, which is used to integrate the Au4f signal and to fit C1s and S2p high-resolution peaks.

\section{Contact angle measurements}

Water contact angle measurements were carried out using an OCA 15 Plus device, DataPhysics (Germany) based on the sessile drop method. A small drop ( $0.7 \mu \mathrm{L})$ of Milli-Q® water were deposited onto the UFG surface and the shape of the drop formed on the surface was analyzed using SCA 20 contact angle analysis software. The contact angle was measured at several points and an average value was extracted.

\section{RESULTS AND DISCUSSION}

The used substrates of ultraflat gold (UFG) were always freshly stripped before the application of the diverse alkanethiol films. In order to manipulate and ultimately control the local nanometer and molecular-scale order of the self-assembled layers we present here 
mainly the two approaches, first, applying two subsequent steps of micro-contact printing ( $\mu$ cp) and, secondly, back-filling the space between the areas initially applied in a single $\mu$-cp step. 1- Hexa- and 1-octadecanethiol $\left(\mathrm{C}_{16}-\mathrm{SH}\right.$ and $\mathrm{C}_{18}$ - $\left.\mathrm{SH}\right)$ long chain-length alkanethiols were chosen in this study for their ability to form stable SAMs.

\section{Double printing}

For the double-print approach, a freshly stripped UFG surface was first micro-contact printed with 1-hexadecanethiol $\left(\mathrm{C}_{16}-\mathrm{SH}\right)$ and subsequently, in a second independent step, double printed with 1-octadecanethiol $\left(\mathrm{C}_{18}-\mathrm{SH}\right)$. Wettability measurements of the UFG surface before and after each printing step yielded water contact angles of $\theta_{\text {bareUFG }}=66 \pm 2^{\circ}$, showing a relatively hydrophilic surface for the pristine sample, $\theta_{\mathrm{C} 16 \mathrm{SH}}=99 \pm 2^{\circ}$ after the first, single printing step, and $\theta_{\mathrm{C} 16 \mathrm{SH} / \mathrm{C} 18 \mathrm{SH}}=104 \pm 2^{\circ}$ for the double-printed surface. The contact angle of the freshly cleaved gold surface agrees well with previously reported contact angle values. $^{27,28}$ After a single-step $\mathrm{C}_{16}$-SH micro-contact printing the surface hydrophobicity increases due to the presence of the patterned, partially covering, SAM regions, which display a lower surface energy. Upon a second printing step with $\mathrm{C}_{18}-\mathrm{SH}$, the surface becomes then even slightly more hydrophobic as a result of stronger attractions between longer chains and an increase in thiol-covered area.

Figure 2 shows a comparison of the single $\mathrm{C}_{16}-\mathrm{SH}(\mathrm{SP})$ and double $\mathrm{C}_{16}-\mathrm{SH} / \mathrm{C}_{18}-\mathrm{SH}$ pattern (DP) layers on UFG as obtained by AFM imaging. Height measured images nicely show clear overlapping stamp regions after the two printing steps. Upon a second printing step, a well-defined boundary between the two squares (single and double printed) can be distinguished (Figure 2c). The height profiles in the non-overlapping regions indicate the presence of compact layers with average thicknesses of $1.7 \pm 0.2 \mathrm{~nm}$ and $2.0 \pm 0.2 \mathrm{~nm}$ for $\mathrm{C}_{16}$-SH and $\mathrm{C}_{18}$-SH SAMs, respectively. As expected, the $\mathrm{C}_{18}$-SH SAM single pattern region 
formed during the second printing step shows a larger thickness than $\mathrm{C}_{16}-\mathrm{SH}$, the difference corresponding to the difference in alkyl length between the two alkanethiols $(\sim 0.3 \mathrm{~nm})$ considering the inclination angle and respective projection of the molecule length. In the overlapping region the thickness of the layer is similar though frequently even slightly lower than that of the single $\mathrm{C}_{16}$-SH pattern. This indicates that the later offered $\mathrm{C}_{18}-\mathrm{SH}$ molecules do not displace the originally applied $\mathrm{C}_{16}-\mathrm{SH}$ molecules of the initial print. In some cases, especially around the overlapping regions of the two print areas the longer molecules rather fill in the possible defects present the original pattern.
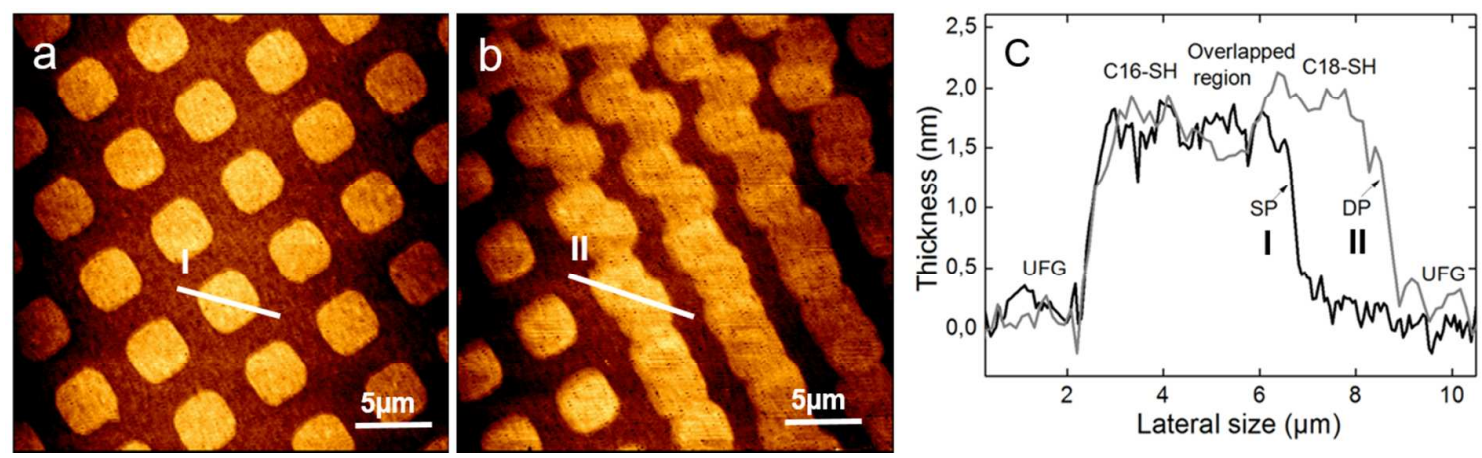

Figure 2. AFM images of (a) single $\mathrm{C}_{16}-\mathrm{SH}$ patterned (SP), (b) double $\mathrm{C}_{16}-\mathrm{SH} / \mathrm{C}_{18}-\mathrm{SH}$ patterned (DP) UFG regions and (c) combined thickness profile of a single printed $\mathrm{C}_{16}-\mathrm{SH}$ square (black solid line) and overlapping single printed $\mathrm{C}_{16^{-}} \mathrm{SH}$ and double printed $\mathrm{C}_{16^{-}}$ $\mathrm{SH} / \mathrm{C}_{18}$-SH squares (gray solid line).

Literature reports on sequential printing are restricted to micro-contact printing of 1decanethiol or 1-dodecanethiol onto a homogeneous, but not very stable, SAM layer of 1adamantanethiolate, which results in micro-displacement or replacement of labile SAM molecules in the well-localized regions by fresh molecules offered by $\mu$-cp.$^{29-31}$ In our case, sequential printing of $\mathrm{C}_{18}$ - $\mathrm{SH}$ is performed onto well-ordered and well-localized $\mathrm{C}_{16}$ - $\mathrm{SH} \mu$ cp-SAMs. Micro-displacement is hindered by the large attraction between our selected long alkyl chains in the $\mathrm{C}_{16}$-SH printed $\mathrm{SAM}$, which also confirms the low lateral diffusion rates 
of the molecules on the substrate. ${ }^{32}$ Eventual molecular physisorption of $\mathrm{C}_{18}$ - $\mathrm{SH}$ on the initial areas cannot be ruled out due to the fact that molecules might not find available gold space within the overlapping regions. A schematic picture of the proposed molecular organization scenario after double patterning is included in Figure 3.

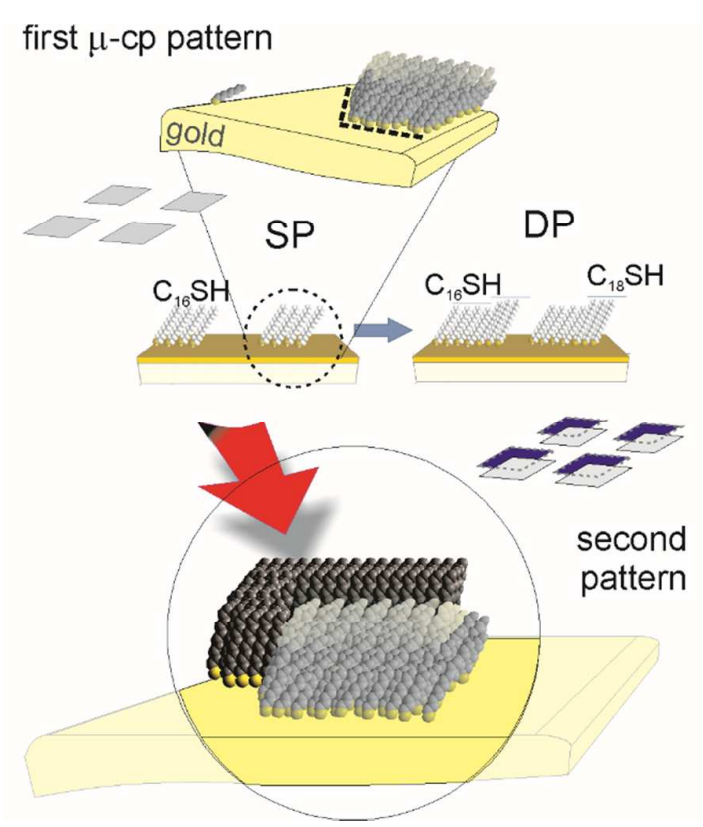

Figure 3. Scheme of the molecular ordering of the SAM layer on the UFG substrate in single $C_{16}$-SH patterned region and SAM layer after the $C_{18}$-SH double printing step.

Complementary XPS spectra were recorded to assess the surface composition before and after each printing step. Figure $4 \mathrm{a}$ shows a comparison of the XPS-survey scans for $\mathrm{C}_{16}-\mathrm{SH}$ single pattern and $\mathrm{C}_{16}-\mathrm{SH} / \mathrm{C}_{18}-\mathrm{SH}$ double pattern UFG surfaces. As expected, Au-related peaks can be clearly observed in lower intensity in both samples, namely intense Au4f and Au4d peaks (Inset of Fig.4a). High-resolution scan for Au4f region is shown as an inset in Figure $4 a$, while the one for $S 2 p$ region is depicted in Figure $4 \mathrm{~b}$. The presence of alkanethiol molecules is confirmed by high-resolution scans for C1s (not shown here) and S2p peaks. 
The increase of the $\mathrm{C}$ and $\mathrm{S}$ by patterning the alkanethiol SAMs is a strong assessment of the surface modification.
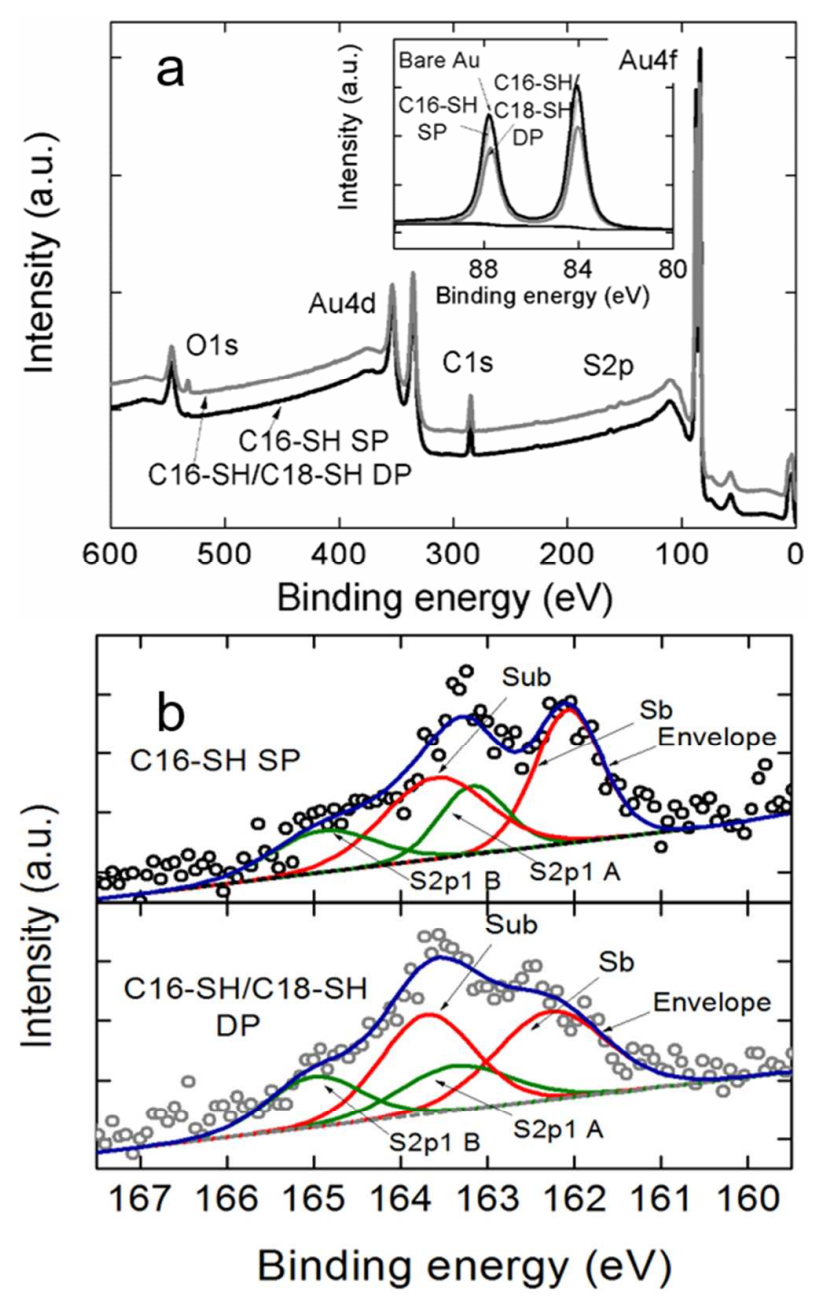

Figure 4. (a) Survey-XPS spectra (double pattern data have been shifted vertically a constant value for better display), inset high-resolution peaks Au4f region. (b) High-resolution peak in the $S 2 p$ region of single $C_{16}$-SH pattern (SP) and double pattern of $C_{16}-S H / C_{18}-S H$ pattern (DP) on the UFG substrate. The circles represent the experimental data and the lines account for fitted values. Blue solid lines account for the envelope fit, red solid lines are fitted $S 2 p_{3}$ values while green solid lines account for fitted $S 2 p_{1}$ values. Baselines are represented by dashed lines.

Importantly, the S2p signal is fitted in two peaks centered at $162.5 \mathrm{eV}$ and $164.0 \mathrm{eV}$, respectively, attributed to bound thiolates $(\mathrm{Sb})$ and unbound (Sub), i.e. only physisorbed 
thiols. ${ }^{33-35}$ The sulphur peaks are fitted by a doublet, with a fixed binding energy difference between the $2 \mathrm{p} 3$ and the $2 \mathrm{p} 1$ components equal to $1.20 \mathrm{eV}$. The height ratio is also fixed according to the doublet combination. The full width at half-height value is kept constant between $2 \mathrm{p} 3$ and $2 \mathrm{p} 1$ components. Each peak is fitted using a fixed combination of Lorentzian (30\%) and Gaussian (70\%). Table 1 contains the corresponding relevant ratios resulting from the quantitative analysis. Upon $\mathrm{C}_{18}$-SH double printing, the $(\mathrm{C}-\mathrm{C}) / \mathrm{Au}$, $(\mathrm{Sb}+\mathrm{Sub}) / \mathrm{Au}$ and $(\mathrm{C}-\mathrm{C}) /(\mathrm{Sb}+\mathrm{Sub})$ elemental ratios display slightly larger values than for the ones observed for single printed UFG surface, indicating that a bigger amount of thiol molecules are present at the surface. The $\mathrm{Au}-4 \mathrm{f}$ and bare Au ratio decreases with higher thiol coverage. The double printing process also increases the amount of covalently bound $v s$ only physisorbed, unbound thiol molecules, in line with a more dense and ordered SAMs. As the $\mathrm{C}_{18}-\mathrm{SH}$ thiol used in the second printing step is slightly longer than the $\mathrm{C}_{16}-\mathrm{SH}$, the $\mathrm{C} /(\mathrm{Sb}+\mathrm{Sub})$ ratio slightly increases by the double printing process.

Table 1. Elemental ratios present on the single and double patterned gold surfaces. Au is referring to the Au4f doublet. The bare Au signal is set to $100 \%$.

\begin{tabular}{|l|l|l|l|l|}
\hline Surface(modification) & $(\mathrm{C}-\mathrm{C}) / \mathrm{Au}$ & $\left(\mathrm{S}_{\mathrm{b}}+\mathrm{S}_{\mathrm{ub}}\right) / \mathrm{Au}$ & $(\mathrm{C}-\mathrm{C}) /\left(\mathrm{S}_{\mathrm{b}}+\mathrm{S}_{\mathrm{ub}}\right)$ & $\mathrm{Au} / \mathrm{Au}_{\text {bare }}[\%]$ \\
\hline $\mathrm{C}_{16}-\mathrm{SH} \mathrm{SP}$ & 0.80 & 0.05 & 16.30 & 88.0 \\
\hline $\mathrm{C}_{16}-\mathrm{SH} / \mathrm{C}_{18}$-SH DP & 1.10 & 0.07 & 16.60 & 65.8 \\
\hline
\end{tabular}

\section{Thiol solution backfilling}

The second approach was carried out by 15 minutes backfilling with an ethanolic solution of $1.0 \mathrm{mM} \mathrm{C}_{18}-\mathrm{SH}$ on an already $\mathrm{C}_{18}-\mathrm{SH}$ microcontact-printed UFG substrate. The wettability measurements of the freshly cleaved UFG surface before and after each step (printing and backfilling) yielded water contact angles of $\theta_{\text {bareUFG }}=70 \pm 3^{\circ}, \theta_{\mathrm{C} 18 \mathrm{SH}}=104 \pm 4^{\circ}$ and $\theta_{\mathrm{C} 18 \mathrm{SH} / \mathrm{C} 18 \mathrm{SH}}=112 \pm 3^{\circ}$. Upon $\mu$-cp the angles increase as a result of the additional presence 
of the $\mathrm{C}_{18}$-SH pattern. Subsequent backfilling with the same molecule resulted into slightly more hydrophobic surfaces due to the larger surface coverage of thiol molecules. Figure 5 shows $\mathrm{AFM}$ images of the $\mathrm{C}_{18}$-SH $\mu$-cp regions before and after backfilling. For the single $\mathrm{C}_{18}$-SH $\mu$-cp the height profiles indicate the presence of compact SAM layers in the covered areas with average thickness of $\sim 2.1 \pm 0.3 \mathrm{~nm}$. Upon backfilling, the difference in height between the thiol-covered and uncovered areas vanishes, indicating that the UFG surface is completely covered by a $\mathrm{C}_{18}$-SH SAM. Interestingly, the morphology of the surface changes displaying a well-defined array with delimited regions whose shape correlates with the original alkanethiol pattern shape. The thickness of these boundaries is $\sim 0.6-0.8 \mathrm{~nm}$ and their lateral dimension is $\sim 1.0 \mu \mathrm{m}$, corresponding to the presence of roughly $\sim 2000$ thiol molecules within the boundary domain, according to the reported molecular distance between neighboring thiol molecules when bound to $\mathrm{Au}(111) .{ }^{36,37}$ The inset of Figure 5e shows a typical phase image which indeed clearly shows the different nature of the boundary area and the extended print area. Phase contrast depends on a change in the mechanical response, i.e. a different local stiffness of the film. In order to confirm the obtained results, the same experiments were repeated several times yielding consistent results (Figure 5). In the presence of a $1.0 \mathrm{mM}$ ethanolic thiol solution, the microcontact printed thiol molecules gain mobility and have the opportunity to restructure. ${ }^{38}$

Molecular reorganization of both printed and backfilled thiol molecules takes place, the backfilled molecules fill the printed layer defects and cover the free UFG surface yielding domain boundaries between the $\mu$-cp thiol regions and the previously uncovered ones. As a result, the edges between these two regions consist of molecules with a different orientation from the thiol molecules away from the edges. Previous AFM studies on alkanethiol solution backfilling consisted on nanografting an already existing SAM, followed by simultaneously 
refilling the tip-shaved areas with a second thiol present in the supernatant ethanol. ${ }^{39}$ These experiments however, did not reveal the appearance of domain boundaries since they were fully performed in an ethanolic environment.
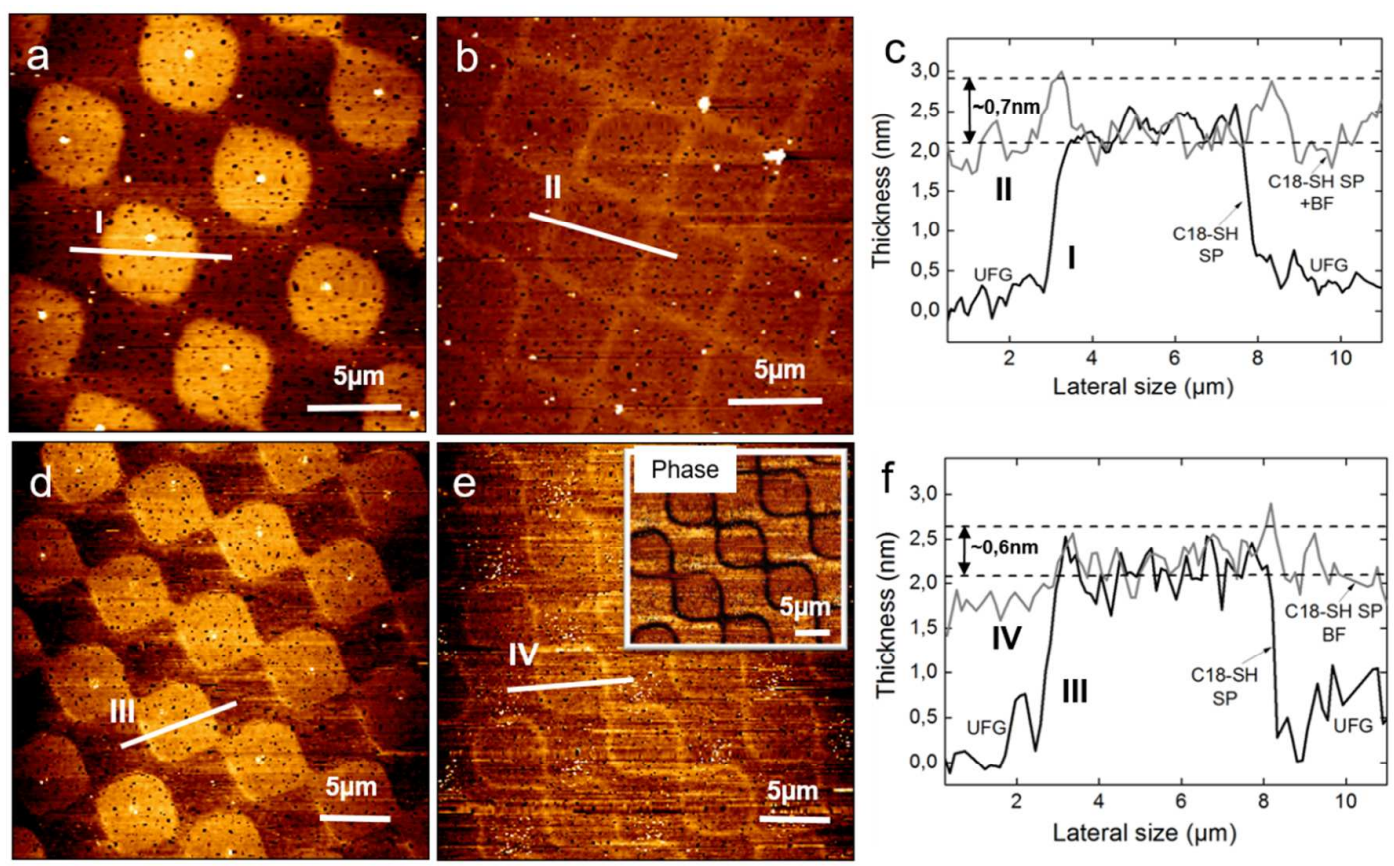

Figure 5. AFM height-profile images of single $C_{18^{-}}$SH patterned ( $a$ and d), backfilled $C_{18^{-}}$ $S H / C_{18}$ SH UFG regions (b and e, Fig. 5e with phase inset) and combined thickness profile (c and f) of a single printed $\mathrm{C}_{18^{-}} \mathrm{SH}$ (black solid line) (SP) and backfilled $\mathrm{C}_{18}-\mathrm{SH} / \mathrm{C}_{18^{-}} \mathrm{SH}$ squares (gray solid line) (BF). Dash lines are added as a guide to the eye representing the vertical thickness of the resulting domain boundaries. 


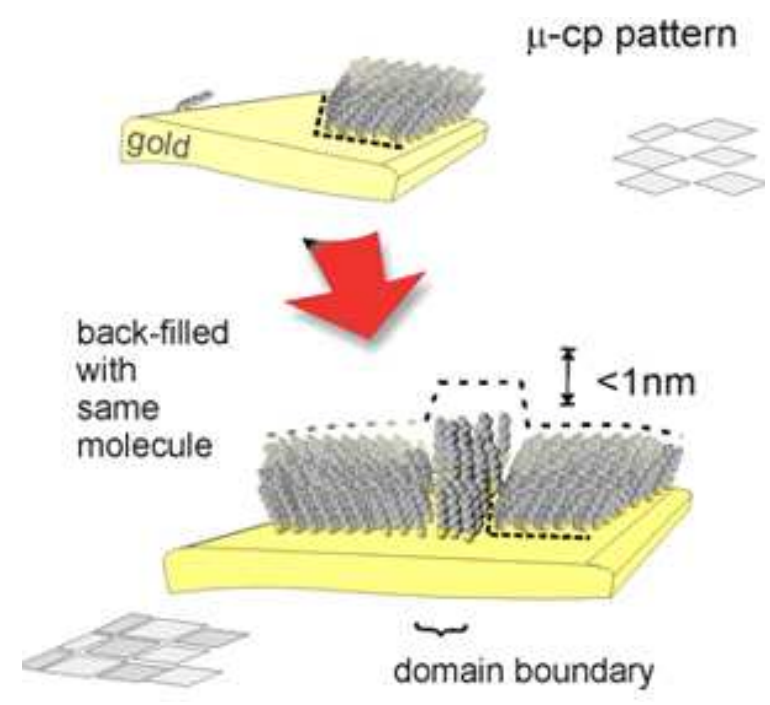

Figure 6. Scheme of the molecular ordering of the SAM layer on the UFG substrate with single $C_{18}$-SH pattern region and SAM layer after backfilling with $C_{18}$-SH molecules.
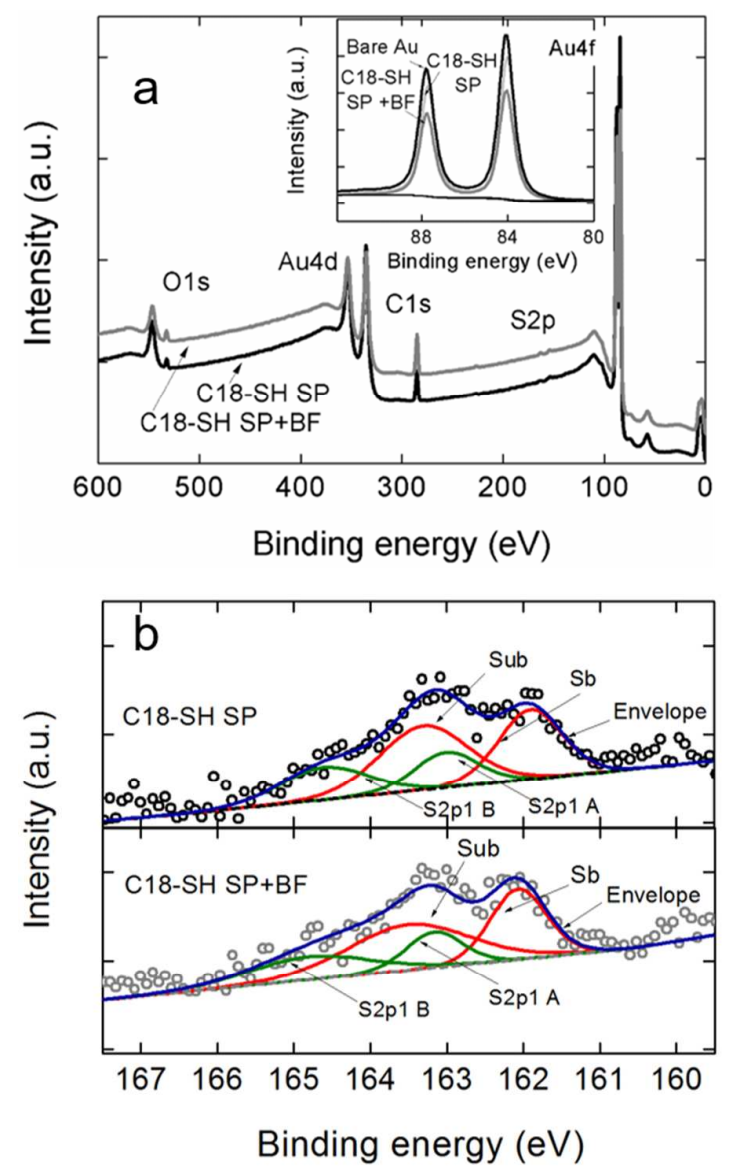

Figure 7. (a) Survey-XPS spectra (double pattern data have been shifted vertically a constant value for better display), inset high-resolution peak in the Au4f region, (b) high- 
Table 2. Elemental ratios present on the single $C_{18}$-SH patterned SAM and same pattern backfilled by $\mathrm{C}_{18}$-SH molecule. Au is referring to the Au4f doublet. Bare Au signal is $100 \%$.

\begin{tabular}{|l|l|l|l|l|}
\hline Surface(modification) & $(\mathrm{C}-\mathrm{C}) / \mathrm{Au}$ & $\left(\mathrm{S}_{\mathrm{b}}+\mathrm{S}_{\mathrm{ub}}\right) / \mathrm{Au}$ & $(\mathrm{C}-\mathrm{C}) /\left(\mathrm{S}_{\mathrm{b}}+\mathrm{S}_{\mathrm{ub}}\right)$ & $\mathrm{Au} / \mathrm{Au}_{\mathrm{bare}}[\%]$ \\
\hline $\mathrm{C}_{18}$-SH SP & 0.80 & 0.04 & 18.20 & 69.5 \\
\hline $\mathrm{C}_{18}$-SH SP/C 18 -SH BF & 1.40 & 0.06 & 24.30 & 57.1 \\
\hline
\end{tabular}

\section{SUMMARY AND CONCLUSIONS}

In this work we propose double microcontact printing and solution backfilling as two different approaches to increase the complexity of laterally structured long-chain alkanethiol self-assembled monolayers on model Au surfaces. The resulting alkanethiol SAMs formed by 
these two strategies were characterized by a complementary set of techniques AFM, water contact angle and XPS.

AFM imaging shows clear overlapping patterns upon 1-hexadecanethiol and subsequent 1octadecanethiol double printing. Both alkanethiols form coexisting compact SAMs that display a well-defined thickness, whose size differs in two methylene groups. No significant microdisplacement of 1-hexadecanethiol upon 1-octadecanethiol printing was observed, owing to the large attraction between long alkyl chains and slow diffusion molecular rates. Interestingly, backfilling with the same molecule resulted in well-delimited nanometer-thick domain boundaries of micrometer lateral dimension in between patterned and backfilled areas. Exposure to an ethanolic alkanethiol solution during the backfilling time enables alkanethiol molecular mobility and the formation of defined domain boundaries. Complementary contact angle and XPS measurements before and after each approach provide consistent information confirming the presence of more hydrophobic, dense and homogeneous SAMs upon the backfilling procedure as compared to double printing.

The presented $\mu$-cp alkanethiol structures are good examples of bottom-up complex SAM formation processes. For our own future research this study provides an opportunity to explore localized dealloying at the nanoscale level in the presence of complex alkanethiol inhibitor layers. Such a well-controlled approach will enable to follow corrosion initiation at specific sites and is especially helpful for local in-situ AFM measurements with a limited field view.

\section{AUTHOR INFORMATION}

Corresponding author E-mail: frank.renner@uhasselt.be 


\section{ACKNOWLEDGMENT}

Financial support by FWO Odysseus program under G0D0115N project is greatly appreciated. We are very grateful to Prof. Andreas Terfort for kindly providing the PDMS stamps.

\section{REFERENCES}

(1) Love, J. C.; Estroff, L. A.; Kriebel, J .K.; Nuzzo, R. G.; Whitesides, G. M. SelfAssembled monolayers of thiolates on metals as a form of nanotechnology. Chem. Rev. 2005, $105,1103-1169$.

(2) Vericat, C.; Vela, M. E., Benítez, G.; Carro, P.; Salvarezza, R. C. Self-assembled monolayers of thiols and dithiols on gold: new challenges for a well-known system. Chem. Soc. Rev. 2010, 39, 1805-1834.

(3) Guo, Q.; Li, F. S. Self-assembled alkanethiol monolayers on gold surfaces: resolving the complex structure at the interface by STM. Phys. Chem. Chem. Phys. 2014, 16, 1907419090.

(4) Maksymovych, P.; Voznyy, O.; Dougherty, D. B.; Sorescu, D. V.; Yates, J. T., Jr. Gold Adatom as a Key Structural Component in Self- Assembled Monolayers of Organosulfur Molecules on Au(111). Prog. Surf. Sci. 2010, 85, 206-240

(5) Chen, H.; Heng, C. K.; Puiu, P. D.; Zhou, X. D.; Lee, A. C.; Lim, T. M.; Tan, S. N. Detection of saccharomyces cerevisiae immobilized on self-assembled monolayer of alkanethiolate using electrochemical impedance spectroscopy. Anal. Chim. Acta 2002, 554, $52-59$.

(6) Gates, B. D.; Xu, Q.; Stewart, M.; Ryan, D.; Willson, C. G.; Whitesides, G. M. New approaches to nanofabrication: molding, printing, and other techniques. Chem. Rev. 2005, $105,1171-1196$. 
(7) Wang, Y.; Im, J.; Soares, J. W.; Steeves, D. M.; Whitten, J. E. Thiol adsorption on and reduction of copper oxide particles and surfaces. Langmuir 2016, 32, 3848-3857.

(8) Laibinis, P. E.; Whitesides, G. M. Self-assembled monolayers of n-alkanethiolates on copper are barrier films that protect the metal against oxidation by air. J. Am. Chem. Soc. 1992, 114, 9022-9028.

(9) Mekhalif, Z.; Riga, J.; Pireaux, J. J.; Delhalle, J. Self-assembled monolayers of ndodecanethiol on electrochemically modified polycrystalline nickel surfaces. Langmuir 1997, $13,2285-2290$.

(10) Belarbi, Z.; Vu, T. N.; Farelas, F.; Young, D.; Singer, M.; Nesic, S. Thiols as volatiles corrosion inhibitors for top-of-the line corrosion, Corrosion 2017, 73, 892-899.

(11) Renner, F. U.; Stierle, A.; Dosch, H.; Kolb, D. M.; Lee, T. L.; Zegenhagen, J. Initial corrosion observed on the atomic scale. Nature 2006, 439, 707-710.

(12) Pareek, A.; Borodin, S.; Bashir, A.; Ankah, G. N.; Keil, P.; Eckstein, G. A.; Rohwerder, M.; Stratmann, M.; Gründer, Y.; Renner, F. U. Initiation and inhibition of dealloying of single crystalline $\mathrm{Cu}_{3} \mathrm{Au}$ (111) surfaces. J. Am. Chem. Soc. 2011, 133, 18264-18271.

(13) Ankah, G. N.; Pareek, A.; Cherevko, S.; Zegenhagen, J.; Renner, F. U. Hierarchical nanoporous films obtained by surface cracking on $\mathrm{Cu}-\mathrm{Au}$ and ethanethiol on $\mathrm{Au}(001)$, Electrochim. Acta 2014, 140, 352-358.

(14) Parida, S.; Kramer, D.; Volkert, C. A.; Rosner, H.; Erlebacher, J.; Weissmuller, J. Volume change during the formation of nanoporous gold by dealloying, Phys. Rev. Lett. 2006, $97,0335504$.

(15) Renner, F. U.; Ankah, G. N.; Bashir, A.; Ma, D.; Biedermann, P. U.; Shrestha, B. R.; Nellessen, M.; Khorashadizadeh, A.; Losada-Pérez, P.; Duarte, M. J.; Raabe, D.; Valtiner, M. Star-shaped crystallographic cracking of localized nanoporous defects. Adv. Mater. 2015, 27, $4877-4882$. 
(16) Wilbur, J. L.; Kumar, A.; Kim, E.; Whitesides, G. M. Microfabrication by microcontact printing of self-assembled monolayers. Adv. Mater. 1994, 6, 600-604.

(17) Smith, R. K.; Lewis, P.A.; Weiss, P. S. Patterning self-assembled monolayers. Prog. Surf. Sci. 2004, 75, 1-68.

(18) Lis, D.; Peremans, A.; Sartenaer, Y.; Caudano, Y.; Mani, A. A.; Dreesen, L.; Thiry, P. A.; Guthmuller, J.; Champagne, B.; Cecchet, F. Self-assembled film organization in fast microcontact printing investigated by sum frequency generation spectroscopy. J. Phys. Chem. C 2009, 113, 9857-9864.

(19) Shrestha, B. R.; Bashir, A.; Ankah, G. N.; Valtiner, M.; Renner, F. U. Localized dealloying corrosion mediated by self-assembled monolayers used as an inhibitor system. Farad. Discuss. 2015, 180, 191-204.

(20) Partes, C.; Yildirim, C.; Schuster, S.; Kind, M.; Bats, J. W.; Zhamikov, M.; Terfort, A. Self-Assembled Monolayers of Pseudo-C2v-Symmetric, Low-Band-Gap Areneoxazolethiolates on Gold Surfaces. Langmuir 2016, 32, 11474-11484.

(21) Kunstman, S. K.; Cyganik, P.; Schupbach, B.; Terfort, A. Relative stability of thiol and selenol based SAMs on Au(111) - exchange experiments. Phys. Chem. Chem. Phys. 2010, $12,4400-4406$.

(22) Adamczyk, L. A.; Anderson, M. R. Impedance differences found in n-alkanethiols prepared by contact printing and solution adsorption. J. Colloid Interface Sci. 2009, 336, 761-765.

(23) Kumar, A.; Whitesides G. M. Features of gold having micrometer to centimeter dimensions can be formed through a combination of stamping with an elastomeric stamp and an alkanethiol "ink" followed by chemical etching. Appl. Phys. Lett. 1993, 63, 2002-2004.

(24) Tien, J.; Xia, Y; Whitesides, G. M. Microcontact printing of SAMs. Thin films 1998, 24, 227-250. 
(25) Libioulle, L.; Bietsch, A.; Schmid, H.; Michel, B.; Delamarche E. Contact inking stamps for microcontact printing alkanethiols on gold. Langmuir 1999, 15, 300-304.

(26) Balmer, T. E.; Schmid, H; Stutz, R.; Delamarche, E.; Michel, B.; Spencer, N. D.; Wolf, H. Diffusion of alkanethiols in PDMS and its implications on microcontact printing $(\mu \mathrm{CP})$. Langmuir 2005, 21, 622-632.

(27) Smith, T. The hydrophilic nature of a clean gold surface. J. Colloid Interface Sci. 1980, $75,51-55$.

(28) Liao, Y. C.; Hargrove, W.; Weeks, B. L. Effect of humidity and hydrophobicity on the tribological properties of self-assembled monolayers. The Scientific World Journal 2013, 2013748295.

(29) Dameron, A. A.; Hampton, J. R.; Smith, R. K.; Muller, T. J.; Gillmor, S. D.; Weiss, P. S. Microdisplacement printing. Nano Letters 2005, 5, 1834-1837.

(30) Saavedra, H. M.; Barbu, C. M.; Dameron, A. A.; Mullen, T. J.; Crespi, V. H.; Weiss, P. S. 1-adamantanethiolate monolayer displacement kinetics follow a universal form. J. Am. Chem. Soc. 2007, 129, 10741-10746.

(31) Mullen, T. J.; Zhang, P.; Srinivasan, C.; Horn, M. W.; Weiss, P. S. Combining electrochemical desorption and metal deposition on patterned self-assembled monolayers. $J$. Electroanal. Chem. 2008, 621, 229-237.

(32) Stranick, S. J.; Parikh, A. N.; Allara, D. L.; Weiss, P. S. A new mechanism for surface diffusion: Motion of a substrate-adsorbate complex. J. Phys. Chem. 1994, 98, 11136-11142.

(33) Castner, D. G.; Hinds, K.; Grainger, D. W. X-ray photoelectron spectroscopy sulfur 2p Study of organic thiol and disulfide binding interactions with gold surfaces. Langmuir 1996, $12,5083-5086$. 
(34) Ishida, T.; Tsuneda, S.; Nishida, N.; Hara, M.; Sasabe, H.; Knoll, W. Surfaceconditioning effect of gold substrates on octadecanethiol self-assembled monolayer growth. Langmuir 1997, 13, 4638-4643.

(35) Ning, Y.; Xie, H.; Xing, H.; Deng, W.; Yang, D. Comparison of self-assembled monolayers of n-alkanethiols and phenylthioureas on the surface of gold. Surf. Interface Anal. 1996, 24, 661-610.

(36) Dubois, L. H.; Nuzzo, R. G. Synthesis, structure and properties of model organic surfaces. Annu. Rev. Phys. Chem. 1992, 43, 437-463.

(37) Yourdshahyana, Y.; Rappe, A. M. Structure and energetics of alkanethiol adsorption on the Au (111) surface. J. Chem. Phys. 2002, 117, 825-833.

(38) Bain, C. D.; Troughton, E. B.; Tao, Y. T.; Evall, J.; Whitesides, G. M.; Nuzzo, R.G. Formation of monolayer films by the spontaneous assembly of organic thiols from solution onto gold. J. Am. Chem. Soc. 1989, 111, 321-335.

(39) Ladnorg, T.; Welle, A.; Heißler, S.; Wöll, C.; Glieman, H. Site-selective growth of surface-anchored metal-organic frameworks on self-assembled monolayer patterns prepared by AFM nanografting. Beilstein J. Nanotechnol. 2013, 4, 638-648. 


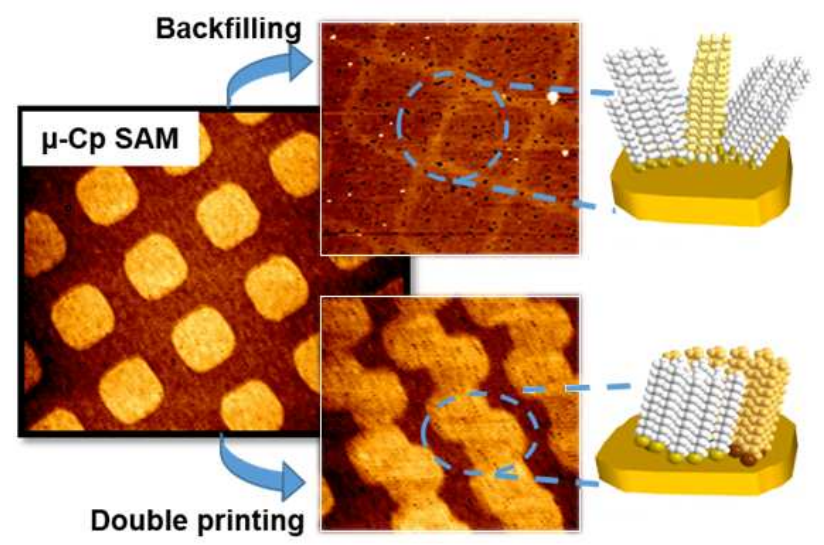

TOC Figure 